\title{
EQUITY
}

Vol. 24, No.2, 2021, 157-174

DOI: 10.34209 /equ.v24i2.2603

P-ISSN 0216-8545 | E-ISSN 2684-9739

Diunggah : Februari 2021

Diterima : September 2021

Dipublikasi : Januari 2022

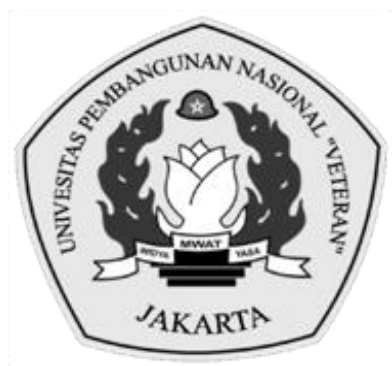

\section{PENGARUH CAPITAL INTENSITY, CORPORATE SOCIAL RESPONSIBILITY, DAN ENVIRONMENTAL UNCERTAINTY TERHADAP TAX AVOIDANCE}

\author{
Muhammad Daffa Wardhana ${ }^{1}$, Dianwicaksih Arieftiara ${ }^{2 *}$, Andy Setiawan ${ }^{3}$ \\ 1m.daffa047@upnvj.ac.id, 2dianwicaksih@upnvj.ac.id, \\ 3andysetiawan2285@upnvj.ac.id \\ 1,2,3Universitas Pembangunan Nasional Veteran Jakarta, Indonesia \\ *Penulis Korespondensi
}

\begin{abstract}
Abstrak
Penelitian ini merupakan penelitian kuantitatif yang bertujuan untuk mengetahui pengaruh capital intensity, corporate social responsibility, dan environmental uncertainty terhadap tax avoidance. Tax avoidance pada penelitian ini menggunakan pengukuran Abnormal Book Tax Difference (ABTD). Sampel penelitian ini berjumlah 138 perusahaan manufaktur yang terdaftar di Bursa Efek Indonesia selama periode 2016-2018. Teknik analisis yang digunakan analisis regresi linear berganda dengan regresi data panel menggunakan program STATA. Hasil dari penelitian ini diperoleh bahwa (1) capital intensity tidak berpengaruh terhadap tax avoidance. (2) corporate social responsibilty berpengaruh terhadap tax avoidance. (3) environmental uncertainty tidak berpengaruh terhadap tax avoidance. Hasil pada penelitian menjelaskan pengungkapan corporate social responsibility yang tinggi dapat mengurangi adanya tindakan tax avoidance. Sehingga penelitian ini dapat membantu para investor dalam memahami faktor-faktor yang dilakukan perusahaan dalam melakukan peghindaran pajak.
\end{abstract}

Kata Kunci: Capital Intensity; Corporate Social Responsibility; Environmental Uncertainty; Tax Avoidance

\begin{abstract}
This research is using quantitative study that aims to investigate the effect of capital intensity, corporate social responsibility, and environmental uncertainty on tax avoidance. Tax avoidance in this study uses the Abnormal Book Tax Difference (ABTD) measurement. The sample of this research was 138 manufacturing companies listed on the Indonesia Listed Exchange in the 2016-2018 period. The analysis technique used is multiple regression analysis with panel data using STATA program. The results indicated that (1) capital intensity has no significant effect on tax avoidance (2) corporate social responsibility has significant effect on tax avoidance (3) environmental uncertainty has no significant effect on tax avoidance. The results of this study explain that disclosure of high corporate social responsibility can reduce tax avoidance. So this research can help investors in understanding the factors that companies do in tax avoidance.
\end{abstract}

Keywords: Capital Intensity; Corporate Social Responsibility; Environmental Uncertainty; Tax Avoidance

Mengutip ini sebagai: Wardhana, M.D., Arieftiara, D., \& Setiawan, A . 2021. The Effect Capital Intensity, Corporates Social Responsibility, and Environmental Uncertainty on Tax Avoidance. Equity, 24(2), 157-174 doi.org/10.34209/equ.v24i2.2603 


\section{PENDAHULUAN}

Pajak yaitu kontribusi wajib dimana bersifat memaksa dibayarkan oleh individu atau badan kepada negara untuk kemakmuran dan kesejahteraan masyarakat (Undang-Undang Nomor 28 Tahun 2007, 2007). Dibandingkan dengan penerimaan pendapatan pemerintah dari sektor lain, sektor perpajakan merupakan sektor penerimaan pendapatan negara yang terbesar. Dibuktikan pada tahun 2019 pendapatan negara sebesar Rp. 2.165,1 T sebesar Rp. 1.786,4 T berasal dari penerimaan pajak (Kevin, 2019). Karena sektor perpajakan memiliki pengaruh yang begitu besar terhadap pendapatan negara, pemerintah berusaha untuk menaikkan pendapatan negara dari sektor perpajakan. Adapun upaya yang telah dilakukan pemerintah pada tahun 2016 telah memberikan pengaruh yang begitu besar terhadap kepatuhan pembayaran pajak, yaitu penetapan kebijakan pengampunan pajak (tax amnesty) berdasarkan ketetapan pada UU No. 11 Tahun 2016 pemerintah berhasil merealisasikan target penerimaan negara sebesar Rp. $135 \mathrm{~T}(81,81 \%)$ dari target penerimaan negara pada ketentuan pengampunan pajak sebesar Rp. 165 T. Namun, upaya pemerintah dalam menaikkan pendapatan negara dari sektor perpajakan tetap mengalami kendala, seperti adanya kegiatan tax avoidance oleh wajib pajak (Swingly \& Sukartha, 2015). Hal ini dibuktikan pada tahun 2019 penerimaan pajak di Indonesia hanya mencapai 84,4\% dari target. Tentunya dalam hal ini tax avoidance menjadi salah satu faktor yang memungkinkan penyebab terjadinya penerimaan pajak tahun 2019 tidak mencapai target.

Tax avoidance adalah usaha taxpayers dalam mencegah tingginya pajak terhutang yang dilakukan secara sah menurut hukum dengan cara tidak melanggar atau mencari kelemahan undang-undang perpajakan (Hutagaol, 2007). Dalam praktik pelaksanaan penghindaran pajak perusahaan dapat meminimalkan beban pajak dengan melakukan peningkatan deductible expense. Deductible expense merupakan biaya yang bisa mengurangi Penghasilan Kena Pajak (PKP) agar laba kena pajak pada perusahaan menjadi relatif kecil (Undang-Undang Republik Indonesia Nomor 36 Tahun 2008, 2008).

Adapun antara lain peluang perusahaan dalam memanfaatkan deductible expense dalam tindakan penghindaran pajak dapat dilakukan dengan meninggikan biaya depresiasi yang dimiliki aset tetap pada perusahaan (Dharma \& Noviari, 2017) dan meninggikan pengeluaran biaya oleh perusahaan dalam merealisasikan pertanggung jawaban sosial perusahaannya (Mao, 2019). Penelitian terdahulu telah menganalisis apa yang mendasari perusahaan membuat tindakan menghindari pajak antara lain adalah capital intensity, corporate social responsibility, dan environmental uncertainty.

Capital intensity adalah investasi perusahaan dalam bentuk aset tetap untuk menghasilkan pendapatan perusahaan yang dilakukan oleh manajer untuk meningkatkan profit bagi perusahaan (Muzakki \& Darsono, 2015). Pada penelitian Wiguna \& Jati (2017) dan Irianto et al. (2017) menyatakan variabel capital intensity tidak memiliki pengaruh signifikan terhadap tindakan tax avoidance yang dilakukan perusahaan. Sedangkan penelitian oleh Nugraha \& Mulyani (2019) dan Dharma \& Noviari (2017) menunjukkan bahwa variabel capital intensity 
berpengaruh signfikan terhadap tindakan tax avoidance yang dilakukan perusahaan.

Corporate social responsibility merupakan tindakan perusahaan dalam memperhatikan dampak sosial dan lingkungan dalam ruang lingkup bisnis yang dilakukan perusahaan untuk memaksimalkan keuntungan dan mengurangi kerugian (Lanis \& Richardson, 2012). Muzakki \& Darsono (2015) dan Dharma \& Noviari (2017) dari penelitiannya menunjukkan jika variabel corporate social responsibility tidak punya pengaruh signifikan kepada tindakan tax avoidance pada perusahaan. Sedangkan penelitian oleh Wiguna \& Jati (2017) menyimpulkan jika corporate social responsibility punya pengaruh signifikan pada tindakan tax avoidance.

Environmental uncertainty merupakan satu diantara faktor eksternal timbulnya tindakan tax avoidance bagi perusahaan. Hal ini dapat terjadi dikarenakan adanya perubahan pada elemen-elemen bisnis, khususnya perubahan pasar produk yang diproduksi oleh perusahan, seperti contoh adanya perubahan pola konsumsi pelanggan dan struktur persaingan produk (Cormier et al., 2013). Penelitian oleh Bimo et al. (2019) menunjukkan variabel environmental uncertainty tidak berpengaruh pada tindakan tax avoidance. Sedangkan penelitiannya oleh Arieftiara et al. (2020) mengatakan jika environmental uncertainty memiliki pengaruh signifikan pada tindakan tax avoidance. yang tidak termasuk sejumlah faktor sebelumnya, ada sejumlah factor lainnya dimana berpengaruh tindakan penghindaran pajak seperti melihat pada firm size dan profitability.

Faktor-faktor terjadinya tindakan penghindaran pajak sebelumnya telah dianalisis oleh beberapa peneliti sebelumnya (Lanis \& Richardson, 2012; Cormier et al., 2013; Huang et al., 2017; Dharma \& Noviari, 2017; dan Arieftiara et al., 2020). Beberapa peneliti mengukur tindakan tax avoidance dengan menggunakan proksi abnormal book tax difference (ABTD), yaitu perbandingan dari nilai book tax difference pada laporan laba akuntansi dan laba fiskalnya yang memiliki nilai abnormal. Capital intensity pengukurannya memakai capital intensity ratio (CIR). Corporate social responsibility pengukurannya dipakai corporate social responsibility index (CSRI). Juga environmental uncertainty pengukurannya melalui tiga proksi yaitu market uncertainty, competitive uncertainty, dan technological uncertainty.

Dampak dari tindakan penghindaran pajak begitu besar pengaruhnya terhadap perekonomian sebuah negara disebabkan pendapatan pajaknya adalah yang diterima negaranya memiliki nilai yang paling besar. Adapun kasus terkait adanya tindakan penghindaran pajak dibuktikan dengan tidak tercapainya target penerimaan negara di setiap tahunnya terlebih adanya bukti kasus pada PT. CocaCola Indonesia. Dengan demikian, peneliti akan melakukan pengujian apakah capital intensity, corporate social responsibility, dan environmental uncertainty berpengaruh kepada tindakan tax avoidance dengan menggunakan proksi ABTD, CIR, CSRI, dan herfindahl index (HI). Penelitian ini didukung oleh variabel kontrolnya merupakan pengukuran perusahaannya juga profitabilitasnya.

Menurut latar belakang sebelumnya, jadi perumusan masalahnya dari penelitian ini yaitu apakah capital intensity berpengaruh terhadap tax avoidance? 
Apakah corporate social responsibility berpengaruh terhadap tax avoidance? Apakah enveironmental uncertainty berpengaruh terhadap tax avoidance?

Menurut perumusan masalahnya, maka pencapaian tujuan yang diinginkan dalam penelitian ini yaitu guna menganalisa pengaruh capital intensity keada tax avoidance, guna menganalisa pengaruhnya corporate social responsibility kepada tax avoidance, dan guna menganalisa pengaruhnya environmental uncertainty kepada tax avoidance.

Penelitian ini memiliki manfaat untuk bisa berkontribusi pada pengembangan literatur maupun sebagai bahan referensi selanjutnya khususnya dalam bidang akuntansi pembahasan mengenai perpajakan. Penelitian ini juga memiliki manfaat bagi para investor agar dapat mengenal keadaan perusahaan lebih dalam berdasarkan capital intensity, corporate social responsibility, dan environmental uncertainty kepada tax avoidance yang dilakukan perusahaannya. Penelitian ini selain itu bisa juga membantu regulator dalam memberikan masukan untuk memperbaiki kebijakan dalam menangani kasus tax avoidance di Indonesia.

\section{TINJAUAN PUSTAKA}

Teori yang berkaitan pada penelitian ini yaitu agency theory. Konsep teori keagenan sesuai pendapat Jensen \& Meckling (1976) menjelaskan terdapat hubunganya perjanjian antar prinsipal (pemilik saham) dengan agennya (pengelola perusahaan atau manajemen). Dimana dalam hubungan kontrak tersebut pihak agen dan pihak prinsipal akan menimbulkan benturan kepentingan kedua belah pihak.

Teori keagenan berkaitan dengan penjelasan mengenai bagaimana cara perusahaan melakukan tindakan tax avoidance agar dapat memenuhi kepentingan pihak prinsipal dan agen. Tax avoidance dilakukan perusahaan atau pihak agen melalui kenaikan biaya-biaya yang bisa mengurangi penghasilan kena pajak agar dapat membayar pajak dengan tingkat yang rendah. Tindakan ini dilakukan agar perusahaan dapat menarik pemegang saham atau pihak prinsipal karena keuntungan perusahaan yang besar sehingga pihak agen pun akan menerima hasil kinerja yang tinggi.

\section{Tax Avoidance}

Tax avoidance yaitu usahanya taxpayers dalam meminimalisir beban pajaknya yang terhutang secara sah menurut hukum karena tidak menentang undang-undang perpajakan yang berlaku. Rahayu (2010) menjelaskan beberapa skema penghindaran pajak yang dilakukan perusahaan, antara lain: Transfer pricing; Tax heaven country; Thin capitalization; Controlled Foreing Corporatioc; dan Treaty shopping..

\section{Capital Intensity}

Capital intensity adalah asset tetap dimana diinvestasikan perusahaan untuk menghasilkan pendapatan perusahaan yang dilakukan oleh manajer untuk meningkatkan profit bagi perusahaan (Muzakki \& Darsono, 2015). Pada penelitian Wiguna \& Jati (2017) dan Irianto et al. (2017) mengatakan variabel capital 
intensity tak memiliki pengaruh signifikansi kepada tindakan tax avoidance yang dilakukan perusahaan. Sedangkan penelitian oleh Nugraha \& Mulyani (2019) dan Dharma \& Noviari (2017) menunjukkan jika variabel capital intensity ada signifikansi pengaruhnya kepada tindakan tax avoidance dimana aset tetap akan mengalami pengurangan kemampuan potensial dalam menghasilkan yang disebabkan adanya depresiasi penyusutan tiap-tiap aset tetap perusahaan.

\section{Corporate Social Responsibility}

Corporate social responsibility adalah tindakan perusahaannya dalam memperhatikan dampak sosial dan lingkungan dalam ruang lingkup bisnis yang dilakukan perusahaan untuk memaksimalkan keuntungan dan mengurangi kerugian (Lanis \& Richardson, 2012). Penelitian dari Muzakki \& Darsono (2015) dan Dharma \& Noviari (2017) menunjukkan jika variabel corporate social responsibility tidak ada pengaruh signifikan kepada tindakan tax avoidance dari perusahaan. Sedangkan penelitian oleh Wiguna \& Jati (2017) menyimpulkan jika corporate social responsibility punya signifikansi pengaruhnya pada tindakan tax avoidance. Hasil penelitiannya menjelaskan tingginya CSR disclosure perusahaan berbanding lurus dengan tindakan tax avoidance perusahaan.

\section{Environmental Uncertainty}

Environmental uncertainty merupakan salah satu faktor eksternal timbulnya tindakan tax avoidance bagi perusahaan. Hal ini dapat terjadi dikarenakan adanya perubahan pada elemen-elemen bisnis, khususnya perubahan pasar produk yang diproduksi oleh perusahan, seperti contoh adanya perubahan pola konsumsi pelanggan dan struktur persaingan produk (Cormier et al., 2013). Penelitian oleh Bimo et al. (2019) menunjukkan variabel environmental uncertainty tidak berpengaruh pada tindakan tax avoidancenya. Tetapi penelitian oleh Arieftiara et al. (2020) mengatakan jika environmental uncertainty memiliki pengaruh signifikan pada tindakan tax avoidance. Hasil penelitian menyiratkan bahwa dalam keadaan lingkungan bisnis yang sangat tidak pasti perusahaan tetap memiliki tanggung jawab kepada para stakeholder.

\section{Pengaruh Capital Intensity terhadap Tax Avoidance}

Capital Intensity diartikan sebagai investasi perusahaan pada aktiva tetap untuk menghasilkan pendapatan perusahaan. Hampir seluruh fixed asset akan mengalami penurunan fungsi setiap tahunnya dan akan menjadi beban depresiasi. Beban pada penyusutan ini akan mempengaruhi jumlah kewajiban pajak yang dibayarkan perusahaan, karena meningkatnya biaya penyusutan akan menurunkan laba perusahaan. Adanya beban penusutan menjadikan tarif pajak semakin efektif sehingga menjadi strategi perusahaan untuk menaikkan laba demi kepentingan prinsipal.

\section{$H_{1}$ : Capital Intensity berpengaruh terhadap Tax Avoidance.}

\section{Pengaruh Corporate Social Responsibility terhadap Tax Avoidance}

Corporate Social Resposbility (CSR) diartikan sebagai tindakan perusahaan dalam melakukan tanggung jawab sosial pada lingkup operasinya (Lanis \& Richardson, 2012). Biaya yang dikeluarkan perusahaan untuk melaksanakan 
program CSR termasuk komponen biaya deductible, artinya biaya tersebut dapat dikurangkan PKP. Dengan pengurangan beban yang dikeluarkan, perusahaan dapat melaporkan profit yang lebih besar. Hal ini dilakukan perusahaan agar dapat memenuhi harapan para pemilik modal.

\section{H2: Corporate Social Responsibility berpengaruh terhadap Tax Avoidance.}

\section{Pengaruh Environmental Uncertainty terhadap Tax Avoidance}

Environmental Uncertainty adalah satu diantara faktor eksternalnya dimana bepengaruh kepada penindakan tax avoidance bagi perusahaan. Ketidakpastian lingkungan dapat terjadi dikarenakan adanya perubahan pada elemen-elemen bisnis, khususnya perubahan pasar produk (Cormier et al., 2013). Berdasarkan teori keagenan, dalam menghadapi ketidakstabilan perusahaan akan menimbulkan perbedaan kepentingan dari kedua belah pihak. Hal ini digambarkan ketika perusahaan mengambil langkah untuk tetap dapat memenuhi harapan dan kepentingan para pemilik modal. Tindakan dan langkah strategis yang diambil manajer dapat melalui strategi pengelolaan pajak dan tindakan tax avoidance agar beban yang dibayarkan perusahaan untuk membayar kewajiban pajak tidak terlalu memberatkan, sehingga laba yang akan dilaporkan dapat menarik perhatian para pemilik modal.

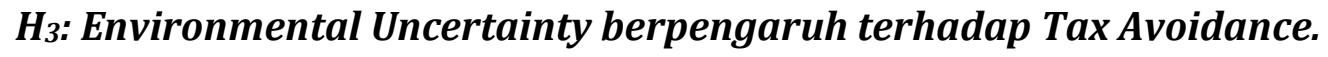

\section{METODOLOGI PENELITIAN}

Populasi pada penelitian kali ini yaitu 142 perusahaannya pada sektor manufaktur dimana didaftarkan pada Bursa Efek Indonesia (BEI) periode 2016 hingga dengan 2018. Populasi pada penelitian yakni perusahaan sektor manufaktur dikarenakan besarnya pengaruh perusahaan manufaktur mengenai perekonomian negara berdampak besar terhadap kontribusi penerimaan pajak oleh pemerintah. Tingginya angka pertumbuhan perusahaan manufaktur memiliki perbandingan searah dengan meningkatnya profitabilitas yang didapat oleh perusahaan, sehingga hal ini berhubungan adanya praktik tax avoidance dibuat agar perusahaannya bisa memaksimalkan laba melalui pengurangan beban pajaknya dimana akan dibayar. Maka dari itu, penulis akan melakukan penelitiannya semakin dalam tentang pengaruh dimana menjadi pembahasan kepada timbulnya penghindaran pajak di perusahaan manufaktur. Teknik mengambil sampelnya memakai purposive sampling yang memiliki ciri tertentu, yaitu:

1. Perusahaannya dimana bergerak pada bidang manufaktur dan tercatat di BEI pada 2016-2018.

2. Perusahaannya dimana belum delistingnya dari BEI tahun 2016-2018.

3. Perusahaannya dimana menghasilkan laporannya tahunan lengkap dan laporan keuangan yang berkaitan memakai variabel ditelitinya.

Menurut kriterianya itu terdapat 138 perusahaan dimana menjadi sampel pada penelitiannya. 


\section{Operasionalisasi Variabel dan Pengukuran}

\section{Tax Avoidance}

Tax Avoidance diukur menggunakan abnormal BTD (ABTD), sesuai dengan pengukuran (Darma et al., 2018). Metode abnormal BTD merupakan modifikasi dari pengukuran BTD dimana cara pengukuran abnormal BTD menggunakan total biaya yang masih harus dibayar dalam regresi BTD agar mendapatkan informasi mengenai manajemen dalam yang berkaitan dengan tujuan perusahaan melakukan tax avoidance (Darma et al., 2018). Rumus 1 menunjukan rumus pengukuran untuk perhitungan ABTD.

Rumus 1. Rumus Perhitungan BTD

$\mathrm{BTD}_{\mathrm{it}}=\frac{{\text { PreTax } \text { Income }_{\mathrm{it}}}-\left(\frac{\text { Tax Expense }_{\mathrm{it}}}{\text { Tax Rate }_{\mathrm{it}}}\right)}{\text { Total Asset }_{\mathrm{it}-1}}$

Keterangan :
1. BTDit
: Book Tax Difference
2. PreTax Income
: Laba Akuntansi
3. Tax Expenses
: Beban Pajak Kini
4. Total Asset $t_{i, \mathrm{t}-1}$
: Total Aset Tahun Sebelumnya

Kemudian, langkah kedua mengukur perhitungan sisa dari persamaan regresi total BTD dengan Rumus 2 seperti ditunjukan dibawah ini.

Rumus 2. Rumus Perhitungan ABTD

$\mathrm{BTD}_{\mathrm{it}}=\beta 1+\beta 2+$ Total Akrualit $+\varepsilon t$

Keterangan:
1. BTD it
: Book Tax Difference
2. Total Akrual : $\frac{\text { NIit-OCFit }}{\text { Total Asset }_{\text {it }}}$

Abnormal Book Tax Difference (ABTD) adalah residual value (nilai sisa) dari regresi rumus 2 .

\section{Capital Intensity}

Capital Intensity diukur menggunakan capital intensity ratio. Capital intensity ratio digunakan untuk mengukur tingkat efisiensi penggunaan teknologi dalam operasional perusahaan untuk memperoleh laba (Arieftiara et al., 2017). Rumus 3 merupakan perhitungan capital intensity ratio berdasarkan Defond \& Hung, (2003).

Rumus 3. Rumus Perhitungan Capital Intensity Ratio

Capital Intensity ratio $=\frac{\text { Total Net Fixed Asset }}{\text { Penjualan }}$ 


\section{Corporate Social Responsibility}

Corporate Social Responsibility (CSR) menggunakan pengukuran variabel dummy berdasarkan indeks GRI G4 yang terdiri oleh 91 indikator. Rumus 4 dibawah ini menunjukan rumus perhitungan CSRI.

\section{Rumus 4. Rumus Perhitungan CSRI}

$C S R I j=\frac{\text { Point Indikator Yang Dilaksanakan }}{\text { Jumlah Kriteria Disclosure CSR Perusahaan }}$

\section{Environmental Uncertainty}

Environmental uncertainty diukur menggunakan ketidakpastian persaingan, dimana ketidakpastian persaingan ini akan menunjukkan tingkatan bisnis pada industri yang sama untuk mengetahui derajat intensitas kompetitif yang lebih tinggi (Arieftiara et al., 2020). Ketidakpastian persaingan lingkungan dihitung dengan Rumus 5 dibawah ini.

Rumus 5. Rumus Perhitungan Herfindahl Index

$$
\begin{aligned}
\mathrm{Hi}=\sum\left(\frac{\text { Penjualan Perusahaan } i}{\text { Penjualan Sektor Industri Manufaktur }}\right)^{2} \ldots \ldots \ldots \\
\text { Keterangan: } \\
\mathrm{Hi}=\text { Herfindahl Index }
\end{aligned}
$$

\section{Ukuran Perusahaan}

Ukuran perusahaannya diukur menggunakan totalan aktivanya dikarenakan ukuran perusahaannya diklasifikasikan berdasarkan $L n$ total aktiva (Prasetyorini, 2013). Ukuran perusahaan dihitung dengan rumus 6 dibawah ini.

\section{Rumus 6. Rumus Perhitungan CSRI}

$$
\text { Ukuran Perusahaan }=\text { Ln Total Aktiva }
$$

\section{Profitabilitas}

Profitabilitasnya diukur menggunakan return on assets (ROA). ROA dipakai guna pengukuran kemampuannya perusahaan menggunakan asetnya guna memperoleh laba bersih (Wiranata \& Nugrahanti, 2013). Rumus 7 dibawah ini menunjukan perhitungan ROA.

\section{Rumus 7. Rumus Perhitungan ROA}

$$
R O A=\frac{\text { Laba Setelah Pajak }}{\text { Total Aset }}
$$

\section{HASIL DAN PEMBAHASAN}

Statistik deskriptifnya dibuat supaya bisa memberi penjelasan secara umum atas sejumlah variabel dimana dipakai pada penelitian. Adapun hasil dari statistik deskriptifnya yang diolah menggunakan STATA v.16. 
Tax avoidance yang diukur menggunakan ABTD total datanya sejumlah 280 data mempunyai nilai rata-ratanya 0,00456 dan mempunyai nilai minimumnya sejumlah $-0,06617$ juga nilai maksimumnya sejumlah 0,07188 . Nilai rata-ratanya di ABTD menunjukkan bahwa penindakan tax avoidance pada perusahaannya sampel mempunyai nilai rendah. Capital intensity yang diukur menggunakan CIR memiliki nilai rata-rata sebesar 0,46604 dengan nilai minimun 0,02089 dan nilai maksimum 2,17003. Nilai rata-rata pada CIR menunjukkan bahwa sebesar $47 \%$ nilai aset tetapnya dimana diperoleh perusahaannya mempunyai pengaruh besar dalam meningkatkan pendapatan perusahaan. Corporate social responsbility dimana pengukurannya memakai CSRI mempunyai penilaian rata-ratanya sejumlah 0,08167 dan nilai minimum 0,01099 juga nilai maksimum 0,20870. Nilainya rata-rata pada CSRI menunjukkan bahwa sebesar $8 \%$ perusahaan pada sampel penelitian mengungkapkan kegiatan tanggung jawab sosial perusahaan berdasarkan GRI G4 disclosure. Environmental uncertainty yang diukur menggunakan herfindahl index (HI) mempunyai rata-ratanya 0,00004 dengan nilai minimumnya 0,00000 juga nilai maksimumnya 0,00128 . Nilai rata-ratanya pada $\mathrm{HI}$ memperlihatkan nilai rata-ratanya penjualan perusahaan di sampel penelitian terhadap total keseluruhan penjualan perusahaan sampel penelitian. Nilai HI yang rendah menandakan bahwa intensitas persaingan pada industri penelitian memiliki daya saing yang tinggi.

Tabel 1. Tabel Statistik Deskriptif

\begin{tabular}{lrrrrr}
\hline Variabel & Obs & Mean & Std. Deviasi & Min & Max \\
\hline ABTD & 280 & 0,00456 & 0,02671 & $-0,06617$ & 0,07188 \\
CIR & 280 & 0,46604 & 0,34609 & 0,02089 & 2,17003 \\
CSRI & 280 & 0,08167 & 0,04682 & 0,01099 & 0,20879 \\
HI & 280 & 0,00004 & 0,00014 & 0,00000 & 0,00128 \\
SIZE & 280 & 28,19979 & 1,26576 & 25,21557 & 31,55276 \\
ROA & 280 & 0,04064 & 0,05281 & $-0,10729$ & 0,22731 \\
\hline
\end{tabular}

Sumber: Output STATA 16.0, Data Diolah Penulis

Ukuran perusahaan dimana pengukurannya memakai SIZE mempunyai nilai rata-ratanya sebanyak 28,19979 yang nilai minimumnya 25,21557 dan nilai maksimum 31,55276. Nilai rata-rata pada SIZE menunjukkan nilai logaritma naturalnya totalan asset perusahaannya di sampel penelitiannya mempunyai nilai rata-ratanya sebanyak 28,19979 . Profitabilitasnya dimana pengukrannya memakai ROA mempunyai nilai rata-ratanya sebanyak 0,04064 yang nilai minimumnya 0,10729 juga nilai maksimumnya 0,22731. Nilai rata-ratanya pada profitabilitasnya menjelaskan bahwa sejumlah 4,06\% perusahaan pada sampel penelitian yang berhasil memiliki nilai efektifitas yang banyak pada pengelolaan asetnya dimana diperoleh guna mendapatkan pendapatan yang besar.

\section{Uji Asumsi Klasik}

Penguian asumsi secara klasik dalam penelitian ini termasuk pengujian normalitas, uji multikolinearitas, dan pengujian heterokedastisitasnya. 
Tabel 2. Hasil Uji Skewness/Kurtosis

\begin{tabular}{cccccc}
\hline Variabel & Obs & Pr (Skewness) & Pr (Kurtosis) & Adj chi2(2) & Prob $>$ chi2 \\
\hline Simpan_data 1 & 280 & 0,1159 & 0,7459 & 2,59 & 0,2734 \\
\hline
\end{tabular}

Sumber: Output STATA 16.0, Data Diolah Penulis

Berdasarkan tabel 4, hasil uji normalitas yang menggunakan uji skewness/kurtosis telah berdistribusi normal dengan probabilitas > 0,05 yaitu dengan nilai 0,2734 . Bisa diambil kesimpulannya jika pada penelitian ini model regresinya telah melengkapi asumsi normalitas.

Tabel 3. Uji Multikolinearitas

\begin{tabular}{lcc}
\hline \multicolumn{1}{c}{ Variabel } & VIF & $\mathbf{1 / V I F}$ \\
\hline SIZE & 1,60 & 0,624355 \\
\hline HI & 1,47 & 0,678903 \\
\hline CIR & 1,16 & 0,864244 \\
\hline ROA & 1,12 & 0,889665 \\
\hline CSRI & 1,08 & 0,925231 \\
\hline \multicolumn{1}{c}{ Mean VIF } & $\mathbf{1 , 2 9}$ \\
\hline
\end{tabular}

Sumber: Output STATA 16.0, Data Diolah Penulis

Pada penelitian ini diketahui nilai VIF juga Tolerance memiliki nilainya VIF $\leq 10$ dan Tolerance $\geq 0,10$, artinya hasil pada penelitian ini tiap variabel independen tidak memiliki korelasi.

Tabel 4. Uji Breusch-Pagan (Uji Heterokedastisitas)

\begin{tabular}{cc}
\hline Probability Standarized & 0,5782 \\
\hline chi2 & 0,05 \\
\hline
\end{tabular}

Sumber: Output STATA 16.0, Data Diolah Penulis

Pada penelitian ini diketahui bahwa nilai $\mathrm{P}$ value $>$ chi squares sebesar 0,5782, artinya hasil uji breusch-pagan pada penelitian ini menunjukkan tidak mendeteksi adanya masalah heterokedastisitas.

\section{Regresi Data Panel}

Penelitian ini memakai peregresian data panel dikarenakan datanya pada penelitian memiliki karakteristik khsus perpaduan antara cross section dan time series. Terdapat tiga pilihan modelnya pada peregresian data panelnya yaitu Common Effect Model (CEM), Fixed Effect Model (FEM), dan Random Effect Model (REM). Untuk membuat pengujian model peregresian data panelnya dilakukan Uji Chow, Uji Lagrange Multiplier, dan Uji Hausman.

Tabel 5. Uji Chow

\begin{tabular}{cc}
\hline Probability restricted & 0,0000 \\
\hline A & 0,05 \\
\hline
\end{tabular}

Sumber: Output STATA 16.0, Data Diolah Penulis 
Uji Chow dipakai guna penentuan mode penelitian paling baik antar CEM dan FEM. Berdasarkan output STATA pada gambar di atas dapat dijelaskan bahwa nilai Prob. $\mathrm{F}$ value $<\alpha$ artinya hasil tersebut menggambarkan jika model peregresian data panelnya secara tepatnya pada penelitian ini memakai FEM.

Tabel 6. Uji Lagrange Multiplier

\begin{tabular}{cc}
\hline Probability restricted & 0,0000 \\
\hline A & 0,05 \\
\hline
\end{tabular}

Sumber: Output STATA 16.0, Data Diolah Penulis

Uji Lagrange Multiplier digunakan untuk menentuan mode penelitian terbaik antara CEM dan REM. Berdasarkan output STATA pada gambar sebelumnya bisa diuraikan jika nilai $\mathrm{P}$ value $<\alpha$ artinya hasil tersebut menggambarkan jika model peregresian data panelnya secara tepat pada penelitian ini memakai REM.

Tabel 7. Uji Hausman

\begin{tabular}{cc}
\hline Probability restricted & 0,0000 \\
\hline A & 0,05
\end{tabular}

\section{Sumber: Output STATA 16.0, Data Diolah Penulis}

Uji Hausman digunakan guna penentuan model penelitian paling baik antar FEM dan REM. Berdasarkan output STATA pada gambar sebelumnya bisa diuraikan jika nilai $\mathrm{P}$ value $>$ chi squares. Artinya hasil tersebut menggambarkan jika model peregresian data panelnya secara tepatnya pada penelitian ini memakai FEM.

Hasil dari pengujian regresi data panelnya di penelitian ini menunjukkan bahwa model Fixed Effect Model (FEM) merupakan hasil model terbaik yang dapat digunakan pada model regresi penelitian ini.

\section{Diskusi dan Pembahasan}

Untuk mengetahui apakah pengaruh yang dimiliki CIR, CSRI, dan HI pada tax avoidance penelitian ini menggunakan pengujian berdasarkan regresi data panelnya. Berdasarkan hasil pengujian regresi data panelnya model pada penelitian menggunakan fixed effect model. Untuk menentukan adanya pengaruh melalui setiap variabelnya di penelitian ini memakai tiga tingkatan signifikansi berbeda yaitu $1 \%, 5 \%$, dan $10 \%$.

Berdasarkan hasil dari pengujian pengaruh capital intensity kepada tax avoidance dengan cara parsial melalui uji statistik $t$ melalui besaran tingkat signifikansi $10 \%$ dapat disimpulkan bahwa capital intensity tak berpengaruh secara signifikansi kepada tax avoidance di perusahaannya manufaktur dimana terdapat daftarnya di Bursa Efek Indonesia. Pada dasarnya perusahaan dengan nilai investasi aset tetap yang tinggi tidak selalu didasari dengan tujuan agar mendapatkan biaya pajak yang rendah yang diperoleh dari hasil pengurangan penyusutan aset tetap setiap tahunnya. Hal tersebut dikarenakan perusahaan memang melakukan investasi pada aset tetap dengan tujuan memaksimalkan 
berjalannya operasional perusahaan. Dilihat dari salah satu contoh perusahaan pada sampel peneltian ini yaitu PT. Toba Pulp Lestari Tbk. hasil pada penelitian menunjukkan nilai maksimum pada capital intensity ratio dari sampel penelitian dengan nilai sebesar 2,170029 dan nilai abnormal book tax difference yang dimiliki yaitu sebesar -0,03707. Nilai abnormal book tax difference yang rendah menandakan bahwa perusahaan tersebut memiliki nilai yang sama atau lebih rendah antar laba akuntansinya dan laba fiskalnya. Berdasarkan hasil itu bisa diambil kesimpulan jika perusahaannya yang mempunyai nilai investasi aset tetap secara meninggi tak berpengaruh secara signifikansi kepada timbulnya tindakan tax avoidance.

Tabel 8. Output olah data Uji Regresi Data Panel setelah outlier

\begin{tabular}{|c|c|c|c|c|c|}
\hline \multirow{3}{*}{ Variabel } & \multicolumn{5}{|c|}{ Regression Model } \\
\hline & \multicolumn{5}{|c|}{ Fixed Effect Model } \\
\hline & Coeffiients & $\mathrm{t}$ & Prob. & $\begin{array}{l}\text { Prediksi } \\
\text { Tanda } \\
\text { Hipotesis }\end{array}$ & Kesimpulan \\
\hline Cons. & $-0,3947153$ & $-1,62$ & 0,108 & & \\
\hline CIR & $-0,0037042$ & $-0,21$ & 0,834 & $\mathrm{H}_{1}:+/-$ & $\mathrm{H}_{1}$ ditolak \\
\hline CSRI & $-0,1191416$ & $-1,85$ & $0,066^{*}$ & $\mathrm{H}_{2}:+/-$ & $\mathrm{H}_{2}$ diterima \\
\hline $\mathrm{HI}$ & $-16,30723$ & $-0,15$ & 0,884 & $\mathrm{H}_{3}:+/-$ & $\mathrm{H}_{3}$ ditolak \\
\hline SIZE & 0,0139242 & 1,59 & 0,114 & & \\
\hline ROA & 0,4594433 & 8,32 & $0,000^{* * *}$ & & \\
\hline $\begin{array}{l}\text { Number of } \\
\text { Obs }\end{array}$ & 280 & & & & \\
\hline $\begin{array}{l}\text { R-squared } \\
\text { Overall }\end{array}$ & 0,0798 & & & & \\
\hline $\begin{array}{l}\text { Prob (F- } \\
\text { Statistic) }\end{array}$ & 0,0000 & & & & \\
\hline
\end{tabular}

Catatan: ***,*** menunjukkan signifikan 1\%,5\%, dan 10\%

Sumber: Output STATA 16.0, Data Diolah Penulis

Hasil penelitiannya ini memiliki kesesuaian pada penelitian terdahulu dari Irianto et al. (2017) dan Wiguna \& Jati (2017) menungkapkan jika capital intensity tak ada pengaruh pada tax avoidance. Hasil tersebut menyatakan bahwa nilai aktiva tetap pada perusahaan tidak memiliki pengaruh yang besar dalam tindakan penghindaran pajak dikarenakan perusahaan memang membutuhkan aset tetap tersebut dalam kepentingan perusahaan dalam mengadakan barang dan jasa. Tapi hasil penelitiannya ini tidak cocok pada penelitian terdahulu oleh Fernándezrodríguez \& Martínez-arias, (2016).

Berdasarkan hasil dari menguji pengaruhnya corporate social responsibility kepada tax avoidance dengan parsial melalui uji statistik $\mathrm{t}$ dengan tingkat signifikansi $10 \%$ bisa diambil kesimpulan jika corporate social responsibility berpengaruh secara signifikansi kepada tax avoidance di perusahaan manufakturnya dimana ada didaftarkan di Bursa Efek Indonesia. Hal ini dikarenakan pada dasarnya sesuai Undang-Undang Republik Indonesia Nomor 36 Tahun 2008 (2008) yang menyatakan bahwa kegiatan sosial pada perusahaan termasuk ke dalam kategori deductible expenses. Sehingga banyak perusahaan yang menyalahartikan hal tersebut menjadi sebuah penyimpangan dengan 
melakukan tindakan penghindaran pajak. Perusahaan menganggap bahwa tindakan CSR hanya menandakan bahwa perusahaan telah melakukan tanggung jawab sosial dengan baik kepada masyarakat agar dapat meningkatkan citra perusahaan tidak mengartikan makna tindakan sosial secara lebih luas dan mendalam, karena pada dasarnya membayar pajak pun sebagai suatu tanggung jawab sosial perusahaan dalam hal mensejahterakan masyarakat secara tidak langsung melalui pemerintah. Hal tersebut dilakukan perusahaan demi menyelamatkan kepentingan sebelah pihak agar biaya yang dikeluarkan untuk membayarkan kewajiban pajak menjadi lebih rendah. Dilihat dari salah satu contoh perusahaan pada sampel peneltian ini adalah PT. Indofood CBP Sukses Makmur Tbk. pada 2018 hasil pada penelitian menunjukkan nilai pengungkapan yang tinggi pada corporate social responsibility index dari sampel penelitian dengan nilai sebesar 0,197802 diikuti oleh nilai abnormal book tax difference yang rendah dibawah nilai rata-ratanya yaitu sebanyak -0,01569. Artinya hal tersebut memperlihatkan jika perusahaannya mempunyai penilaian corporate social responsibility secara tinggi memiliki nilai abnormal book tax difference yang rendah. Menurut hasilnya tersebut bisa diambil kesimpulan jika perusahaan dengan pengungkapan corporate social responsibility yang tinggi berpengauh secara signifikansi kepada tindakan tax avoidancenya. Hal tersebut sesuai pada penelitiannya terdahulu dari Dharma \& Noviari (2017) mengatakan jika perusahaannya melalui pengungkapannya CSR secara sedikit kemungkinan bisa menghindari pajaknya semakin agresif jika perbandigannya terhadap perusahaan dengan pengungkapan CSR secara tinggi. Hasil penelitian ini juga mempunyai kesesuaian oleh penelitian Mao (2019) dimana mengatakan perusahaan mengungkapkan CSR dikarenakan perusahaan tersebut telah melakukan strategi dalam mengelola risiko, dimana risiko tersebut dilakukan perusahaan agar dapat menghindari adanya denda dan kerugian akibat ketidakpatuhan pajak, sehingga perusahaan tersebut memiliki keterlibatan dalam membuat tindakannya tax avoidance. Hasilnya pada penelitian ini tidak memiliki kesesuaian terhadap penelitiannya terdahulu dari Lestari \& Solikhah (2019).

Berdasarkan hasil dari pengujian pengaruh environmental uncertainty kepada tax avoidance secara parsialnya melalui pengujian statistik $t$ dengan tingkat signifikansi 10\% dapat disimpulkan bahwa environmental uncertainty tak berpengaruh secara signifikansi kepada tax avoidance di perusahaan manufaktur dimana terdaftarkan di Bursa Efek Indonesia. Pada sampel penelitian ini memperlihatkan jika secara keseluruhan perusahaannya sampel pada periode 2016-2018 mengalami ketidakpastian lingkungan yang tinggi, dimanadiperlihatkan melalui nilainya herindahl index rendah. Nilai herfindahl index yang rendah dikarenakan tingkat persaingan pada sektor industri manufaktur terlalu tinggi. Dibandingkan dengan nilai abnormal book tax difference pada masing-masing perusahaan tersebut tidak selalu memiliki persamaan nilai yang berpengaruh. Nilai pada abnormal book tax difference yang rendah menunjukkan jika perusahaannya itu tidak membuat ada penghindarannya pajak pada suatu kondisi dihadapinya. Hal ini dibuktikan pada perusahaan sampel penelitian PT. Alkindo Naratama Tbk. pada tahun 2018 yang memiliki nilai herfindahl index yang rendah sebesar 0,0000003554 dengan nilai abnormal book tax difference yang rendah di bawah rata-rata yaitu sebesar 0,000103. Artinya hasil 
penelitian menunjukkan bahwa manajemen perusahaan sampel dalam menghadapi kondisi ketidakpastian lingkungan yang tinggi fokus dalam mengembangkan strategi lain, baik strategi bertahan maupun strategi inovasi bukan mengembangkan strategi pada tindakan penghindaran pajak. Hasil penelitian menunjukkan bahwa manajemen perusahaan sampel dalam menghadapi kondisi ketidakpastian lingkungan yang tinggi fokus dalam mengembangkan strategi lain. Data pada penelitian ini menunjukkan penghindaran pajak bukan sebagai opsi manajer dalam menghadapi ketidakpastian lingkungan yang tinggi. Hasil penelitiannya menyesuaikan terhadap penelitiannya terdahulu oleh Huang et al. (2017) dan Carolina \& Purwantini (2020) yang menjelaskan bahwa tindakan perusahaan dalam menghadapi suatu kondisi ketidakpastian lingkungan yang tinggi cenderung merubah pola strategi dalam melakukan persaingan yang lebih baik setiap tahunnya. Hasil pada penelitiannya ini tak cocok ke penelitian sebelumnya oleh Arieftiara et al. (2020) dan Firmansyah (2020).

\section{SIMPULAN}

Tujuan dilakukannya penelitiannya ini yaitu guna menganalisa pengaruhnya capital intensity, corporate social responsibility, environmental uncertainty kepada tax avoidance menggunakan variabel kontrolnya yaitu pengukuran perusahaannya juga profitabilitas. Penelitiannya dilakukan di perusahaan manufaktur didaftarkan pada Bursa Efek Indonesia (BEI) periode 2016-2018. Adapun pengukuran dimana dipakai pada menghitung tindakan tax avoidance pada perusahaan pada penelitian ini memakai abnormal book tax difference dimana didapat dari hasil regresi book tax difference dengan total akrual. Hasilnya didapatkan dari analisis di penelitian ini yaitu sebagai berikut:

Capital intensity dan environmental uncertainty tak berpengaruh kepada tax avoidance hal ini dikarenakan pada dasarnya perusahaan memiliki aset tetap digunakan dalam mengembangkan operasional perusahaan agar dapat mencapai tujuan perusahaan, ketika mengalami kondisi ketidakpastian lingkungan dalam menghadapi kondisi ketidakpastian lingkungan yang tinggi fokus dalam mengembangkan strategi lain, baik strategi bertahan maupun strategi inovasi bukan mengembangkan strategi pada tindakan penghindaran pajak.

Corporate social responsibility memiliki pengaruh kepada tax avoidance. Menurut Undang-Undang Republik Indonesia Nomor 36 Tahun 2008, 2008 yang menyatakan bahwa kegiatan sosial pada perusahaan termasuk ke dalam kategori deductible expenses. Perusahaan dapat memanfaatkan hal tersebut sebagai pengurangan biaya pajak yang tinggi, artinya perusahaan mengungkapkan CSR berpengaruh terhadap pengurangan biaya pajak hal ini dilakukan perusahaan sesuai dengan kebutuhan pada teori agensi meningkatkan citra perusahaan kepada publik dengan meminimalisir adanya risiko ketidakpatuhan pajak yang diakibatkan tindakan penghindaran pajak. Adapun variabel kontrolnya di penelitian ini adalah pengukuran perusahaannya secara signifikansi tak berpengaruh tetapi profitabilitas berpengaruh signfikan kepada tax avoidance. 
Penelitiannya ini diharapkan dapat berkontribusi untuk mebantu pihak regulator dalam hal memberikan masukan untuk memperbaiki kebijakan dalam menangani kasus tax avoidance di Indonesia serta mebantu pihak investor untuk mengenal keadaan perusahaan berdasarkan capital intensity, corporate social responsibility, dan environmental uncertainty dimana dibuat perusahaannya dalam hal mengetahui bagaimana pengaruh faktor-faktor tersebut kepada manajemen pajak perusahaannya. Penelitian ini memiliki keterbatasan yaitu banyaknya data terkeluarkan. Hal ini didasari pada hasil olahan data yang bernilai kecil sehingga nilai perhitungan pada perusahaan yang memiliki nilai besar harus dikeluarkan agar memenuhi syarat uji pengolahan data. Keterbatasan lain pada penelitian ini yaitu mengukur intensitas persaingan hanya menggunakan data pada perusahaan go public. Diharapkan pada penelitian selanjutnya dapat melakukan intensitas persaingan menggunakan data pada perusahaan go public dan non go public dan menggunakan pengukuran lain pada variabel CSR.

\section{DAFTAR PUSTAKA}

Arieftiara, D., Utama, S., \& Wardhani, R. (2017). Environmental uncertainty as a contingent factor of business strategy choice decision: Introducing an alternative measurement of uncertainty. Australasian Accounting, Business and Finance Journal, 11(4), 116-130. https://doi.org/10.14453/aabfj.v11i4.9

Arieftiara, D., Utama, S., Wardhani, R., \& Rahayu, N. (2020). Contingent fit between business strategies and environmental uncertainty: The impact on corporate tax avoidance in Indonesia. Meditari Accountancy Research, 28(1), 139-167. https://doi.org/10.1108/MEDAR-05-2018-0338

Bimo, I. D., Prasetyo, C. Y., \& Susilandari, C. A. (2019). The effect of internal control on tax avoidance: the case of Indonesia. Journal of Economics and Development, 21(2), 131-143. https://doi.org/10.1108/jed-10-2019-0042

Carolina, V., \& Purwantini, A. H. (2020). Pengaruh Pengendalian Internal , Struktur Kepemilikan, Sales Growth, Ketidakpastian Lingkungan , dan Koneksi Politik terhadap Tax Avoidance (Studi Empiris Pada Perusahaan Manufaktur Yang Terdaftar di BEI Periode.

Cormier, D., Houle, S., \& Ledoux, M. J. (2013). The incidence of earnings management on information asymmetry in an uncertain environment: Some Canadian evidence. Journal of International Accounting, Auditing and Taxation, 22(1), 26-38. https://doi.org/10.1016/j.intaccaudtax.2013.02.002

Darma, R., Dwi, Y., Tjahjadi, J., \& Mulyani, S. D. (2018). Pengaruh Manajemen Laba, Good Corporate Governance, dan Risiko Perusahaan Terhadap Tax Avoidance. 5(2), 137-164.

Defond, M. L., \& Hung, M. (2003). An empirical analysis of analysts 'cash flow. 35, 73-100. https://doi.org/10.1016/S0165-4101(02)00098-8

Dharma, N. B. S., \& Noviari, N. (2017). Pengaruh Corporate Social Responsibility Dan Capital Intensity Terhadap Tax Avoidance. E-Jurnal Akuntansi, 18, 529556. 
Fernández-rodríguez, E., \& Martínez-arias, A. (2016). Do Business Characteristics Determine an Effective Tax Rate? Do Business Characteristics Determine an Effective Tax Rate? Evidence for Listed Companies in China and the. 1475(March). https://doi.org/10.2753/CES1097-1475450604

Firmansyah, A. (2020). The Role Of Managerial Ability In Indonesia: Investment Opportunity Sets, Environmental Uncertainty, Tax Avoidance The Role of Managerial Ability In Indonesia: Investment Opportunity Sets , Environmental Uncertainty Tax. September. https://doi.org/10.18510/hssr.2020.84123

Huang, H., Sun, L., \& Zhang, J. (2017). Environmental uncertainty and tax avoidance. Advances in Taxation, 24, 83-124. https://doi.org/10.1108/S1058749720170000024002

Hutagaol, J. (2007). Perpajakan: Isu-Isu Kontemporer. Graha Ilmu.

Irianto, D. B. S., Sudibyo, Y. A., \& Wafirli, A. (2017). The Influence of Profitability, Leverage, Firm Size and Capital Intensity Towards Tax Avoidance. International Journal of Accounting and Taxation, 5(2), 33-41. https://doi.org/10.15640/ijat.v5n2a3

Jensen, C., \& Meckling, H. (1976). Theory Of The Firm : Managerial Behavior , Agency Costs And Ownership Structure I. 3, 305-360.

cnbcindonesia.com (2019, 12 Desember). Apa Kabar Pak Suryo? Pajak Masih Kurang Rp. 400 T Lebih Nih!. Diakses pada 09 September 2020, dari https://www.cnbcindonesia.com/news/20191212152144-4-122575/apakabar-pak-suryo-pajak-masih-kurang-rp-400-t-lebih-nih

Lanis, R., \& Richardson, G. (2012). Corporate social responsibility and tax aggressiveness: An empirical analysis. Journal of Accounting and Public Policy, 31(1), 86-108. https://doi.org/10.1016/j.jaccpubpol.2011.10.006

Lestari, J., \& Solikhah, B. (2019). The Effect of CSR, Tunneling Incentive, Fiscal Loss Compensation, Debt Policy , Profitability , Firm Size to Tax Avoidance. 8(1), 31-37. https://doi.org/10.15294/aaj.v8i1.23103

Mao, C. W. (2019). Effect of corporate social responsibility on corporate tax avoidance : evidence from a matching approach. Quality \& Quantity, 53(1), 49-67. https://doi.org/10.1007/s11135-018-0722-9

Muzakki, M. R., \& Darsono. (2015). Pengaruh Corporate Social Responsibility Dan Capital Intensity Terhadap Penghindaran Pajak. E-Jurnal Akuntansi, 4(3), 445-452.

Nugraha, M. I., \& Mulyani, S. D. (2019). Peran Leverage Sebagai Pemediasi Pengaruh Karakter Eksekutif, Kompensasi Eksekutif, Capital Intensity, Dan Sales Growth Terhadap Tax Avoidance. Jurnal Akuntansi Trisakti, 6(2), 301. https://doi.org/10.25105/jat.v6i2.5575

Prasetyorini, B. F. (2013). Pengaruh Ukuran Perusahaan, Leverage, Price Earning Ratio dan Profitabilitas terhadap Nilai Perusahaan. Jurnal Ilmu Manajemen (JIM), 1(1).

Rahayu, N. (2010). Evaluasi Regulasi Atas Praktik Penghindaran Pajak Penanaman Modal Asing. Jurnal Akuntansi Dan Keuangan Indonesia, 7(1), 61-78. https://doi.org/10.21002/jaki.2010.04 
Swingly, C., \& Sukartha, I. M. (2015). Pengaruh Karakter Eksekutif, Komite Audit, Ukuran Perusahaan, Leverage, dan Sales Growth pada Tax Avoidance. EJurnal Akuntansi Universitas Udayana, 1, 47-62.

Undang-Undang Republik Indonesia Nomor 28 Tahun 2007 Tentang Perubahan Ketiga Atas Undang-Undang Nomor 6 Tahun 1983 Tentang Ketentuan Umum dan Tata Cara Perpajakan, (2007).

Undang-Undang Republik Indonesia Nomor 36 Tahun 2008 Tentang Perubahan Keempat Atas Undang-Undang Nomor 7 Tahun 1983 Tentang Pajak Penghasilan, (2008).

Wiguna, I. P. P., \& Jati, I. K. (2017). Pengaruh Corporate Social Responsibility, Preferensi Risiko Eksekutif, Dan Capital Intensity Pada Penghindaran Pajak. E-Jurnal Akuntansi, 21, 418-446.

Wiranata, Y. A., \& Nugrahanti, Y. W. (2013). Pengaruh Struktur Kepemilikan Terhadap Profitabilitas Perusahaan Manufaktur di Indonesia. Jurnal Akuntansi Dan Keuangan, 15(1), 15-26. https://doi.org/10.9744/jak.15.1.15-26 
EQUITY, Vol. 24, No.2, 2021, 157-174

Halaman ini sengaja dikosongkan

untuk kepentingan penggenapan halaman 